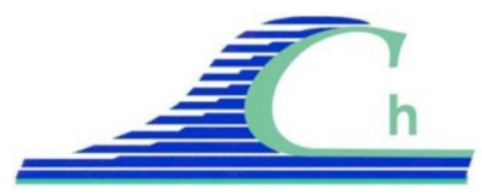

XII ${ }^{\text {ìmes }}$ Journées Nationales Génie Côtier - Génie Civil

Cherbourg, 12-14 juin 2012

DOI:10.5150/jngcgc.2012.053-T C Editions Paralia CFL

disponible en ligne - http://www.paralia.fr - available online

\title{
Large-scale modelling of fine-grained sediment transport: Can we do any better?
}

\author{
Erik A. TOORMAN ${ }^{1}$
}

\author{
1. Hydraulics Laboratory, Civil Engineering Department, Katholieke Universiteit \\ Leuven, Kasteelpark Arenberg 40, box 2448, B-3001 Leuven, Belgium. \\ erik.toorman@bwk.kuleuven.ac.be
}

\begin{abstract}
:
Numerical models have become a major tool for the study of sediment transport problems in coastal engineering. Reviewing the evolution of model progress, it is noticed that advancement has mainly been achieved in higher computational performance, allowing more detailed and even 3D simulation of large-scale problems at a reasonable cost. However, the prediction capacity remained disappointing and has hardly improved since the models are still based on the same basic process descriptions. Over the past 20 years many processes have been studied in more detail. Nevertheless, attempts to incorporate more complicated models for processes such as flocculation and erosion have not really brought the expected improvement.

This paper presents an overview of the major short-comings in presently used sediment transport software. Proposals to incorporate more physics, without increasing the computational cost too excessively, will be presented. New process models have been developed for flocculation and for particle-turbulence interaction in high-concentrated suspensions, and a new bed model, accounting for both consolidation and wave-induced fluidization, is under development. Furthermore, it is demonstrated that estuarine and coastal applications require the distinction between (at least) two floc populations of cohesive sediment and (at least) one sand fraction. Remaining problems can be related to the difficulty to account for the spatial and temporal variability of sediment properties, especially with regard to the bed, and to the effect of bio-engineering agents in the environment. This keeps large uncertainties in the model results which can hardly be reduced.
\end{abstract}

Keywords:

Sediment transport modelling - Cohesive sediment - Flocculation - Particle-turbulence interaction - Bottom friction - Erosion - Sand-mud mixtures

\section{Introduction}

The first sediment transport models, developed in the '70s, solved the depth-averaged continuity equation and momentum equations for the hydrodynamics and an uncoupled sediment transport model for the particles (approximated as monodisperse). In the case of sand, the models are based on empirical bed load or total load formulas, while 
cohesive sediments are dealt with an elementary suspension model (advection-diffusion equation). Since the ' 90 s, with increasing computing power, 3D modelling has become feasible. Hydrodynamics in most codes is solved with the 3D Saint-Venant equations for the horizontal momentum (implying the assumption of a hydrostatic pressure distribution). Momentum and sediment transport equations now require a more complex turbulence closure in order to provide a closure for the vertical mixing. The most popular one is the two-equation $k-\varepsilon$ model. By including the buoyancy destruction term, the effect of density stratification can be accounted for and generates a coupling between hydrodynamics and sediment transport. Because of density gradients, especially in the horizontal direction, the vertical momentum should be solved explicitly in order to account for the non-hydrostatic effects which exist in nature. There is now indeed a trend to allow non-hydrostatic computations, even though they are more costly. Despite all the improvements over the past years, which is mainly noticed in enhanced computing capacities, the quantitative accuracy of sediment transport models (especially of fluxes) remains disappointing. There has been significant progress over the years in understanding why the models are so little reliable and it is acknowledged that many processes are described in a far too empirical and simplified way. Various processes have been studied in detail and many 1DV model studies performed, but these models are too costly (i.e. often requiring too many layers over the vertical) to be implemented into 3D codes applied to large areas. This paper gives an overview of the key processes which need to be improved and presents some recently proposed strategies towards an efficient implementation of several sub-grid scale processes (especially flocculation and particle-turbulence interaction) based on a physical rather than an empirical description. For other processes (especially erosion) the weaknesses and subsequent challenges are discussed.

\section{Settling velocity}

The settling velocity is a major key parameter in sediment transport modelling. It may not be confused with the vertical particle velocity, which corresponds with the net movement of the balance between gravitational settling (characterized by the settling velocity) and the net upward turbulent-induced entrainment. By definition the settling velocity is actually the terminal fall velocity in quiescent water. It can be computed theoretically with the Stokes formula, corrected by a factor to account for drag modulation due to the particle wake at high particle Reynolds numbers (usually the Naumann-Schiller correction).

Unfortunately, in the field, the particle is often present in flowing rather than quiescent water. Therefore, the terminal fall velocity is rarely reached and thus overpredicts the settling velocity necessary in the models. Moreover, the Stokes formula requires particle size and particle diameter as input and is only correct for spherical particles. In nature, particles have varying sizes and shapes, and in the case of cohesive sediments particles 


\section{XII ${ }^{\text {èmes }}$ Journées Nationales Génie Côtier - Génie Civil \\ Cherbourg, 12-14 juin 2012}

are aggregates of compact flocculi (primary aggregates), forming flocs which grow or break up depending on ambient conditions (especially turbulent shear, particle concentrations and the presence of organic matter).

Flocculation of cohesive sediments has been studied extensively since the pioneering work of KRONE (1962) and PARTHENIADES (1962). This resulted in empirical corrections for the settling velocity in terms of turbulent shear and sediment concentration. But these models assumed immediate adaptation to the variation of these parameters, whereas in reality aggregation and break-up requires time. Therefore, kinetic theory has been applied to flocs allowing time-varying properties with appropriate time scales. Nevertheless, neither the simple nor the complex models in general allow much improvement, except for a few exceptional cases. Population balance equation (PBE) modelling has been investigated, but it increases the complexity and the computational time without much gain, because calibration of the many additional model parameters is too difficult from lack of the necessary data.

Recent research at the KULeuven has been investigating the possibility to use PBE theory in a more efficient way. Following, are some interesting conclusions of this work on flocculation:

- Field data show the co-existence of at least two floc populations: flocculi (the basic build-blocs, approximately $10 \mu \mathrm{m}$ size, consisting of compact aggregates which rarely break down into primary particles under field conditions) and micro-flocs (average size of 50-100 $\mu \mathrm{m})$. In the presence of active biogenic polymers macro-flocs $(>200 \mu \mathrm{m})$ or during specific seasons (e.g. in periods of algae bloom) even megaflocs $(>500 \mu \mathrm{m})$ can be formed (LEE et al., 2012a).

- The floc size distribution for each population can be sufficiently accurately described by a log-normal distribution (fig.1). The settling velocity computed with the average particle size $\left(d_{50}\right)$ is found to yield the same settling flux as the integrated flux for each entire population (WANG, 2011). However, representation of all the particles by one single population may yield an error on the sedimentation flux of the order of $50 \%$; this can be reduced to less than $10 \%$ by considering two (or more) distinct populations (LEE et al., 2012b).

Based on these observations, a two-class PBE model has been developed which succeeds in simulating quite well the dynamics of both populations, represented by the mean size (LEE et al., 2011 \& 2012b). In a next step, a continuous floc size distribution per population, described by a simple log-normal distribution, will be implemented in this model, following the idea of MAERZ \& WIRTZ (2009). 


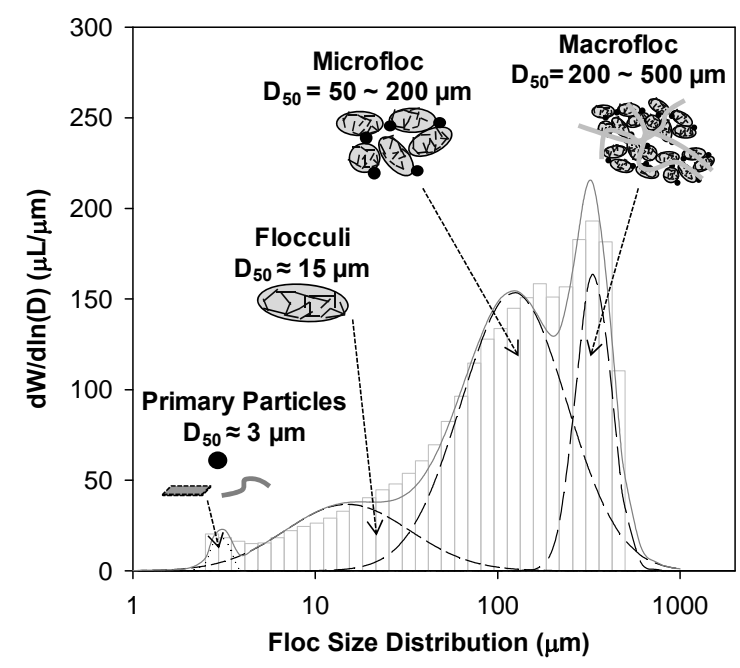

Figure 1. Decomposition of the particle size distribution in four populations for suspended cohesive sediments along the Belgian coast (LEE et al., 2012a).

\section{Bottom roughness}

The bottom boundary condition for hydrodynamics consists of a friction law. Most models apply one or the other form of the quadratic friction law (equivalent to Chézy's friction law). Traditionally, the hydrodynamics model is calibrated individually by tuning the bottom friction coefficient in such a way, that the computed water levels correspond to the observed values. In a few cases, velocity fields are compared. However, detailed comparison of flow patterns with field data often reveals significant discrepancies, especially over the vertical and in shallow areas.

It is acknowledged that for special cases, especially non-dilute conditions, there is a significant drag modulation at the bottom: in the case of sheet flows of sand, the apparent bed roughness increases (SUMER et al., 1996), while for rivers with high mud concentrations drag reduction is observed (WANG \& LARSEN, 1994). Numerical experiments with a $1 \mathrm{DV}$ sediment transport model with $k-\varepsilon$ turbulence closure (TOORMAN, 2000) reveal that drag reduction is caused by turbulence damping due to stratification (buoyancy destruction). This effect results in a change of slope of the logvelocity law, i.e. a reduction of the value of the von Karman parameter appearing in mixing-length theory. Interestingly, this is indeed observed in the laboratory, not only for mud (LI \& GUST, 2000), but also in the sand transport experiments of CELLINO (1998) (figure 2). Nevertheless, in the latter case the velocities keep decreasing with increasing sediment load, indicating increasing friction losses. At the same time, it is observed that the thickness of the inner layer is significantly higher than one would expect in clear water for the same flow energy, suggesting that another turbulent dissipation mechanism must be present, which cannot be due to the macroscopic shear flow. All the available evidence indicates that the explanation must be sought in the 


\section{XII ${ }^{\text {èmes }}$ Journées Nationales Génie Côtier - Génie Civil \\ Cherbourg, 12-14 juin 2012}

existence of an additional turbulence production mechanism, i.e. in the wake of the particles, because of the velocity lag caused by their inertia (especially of importance near the bottom).

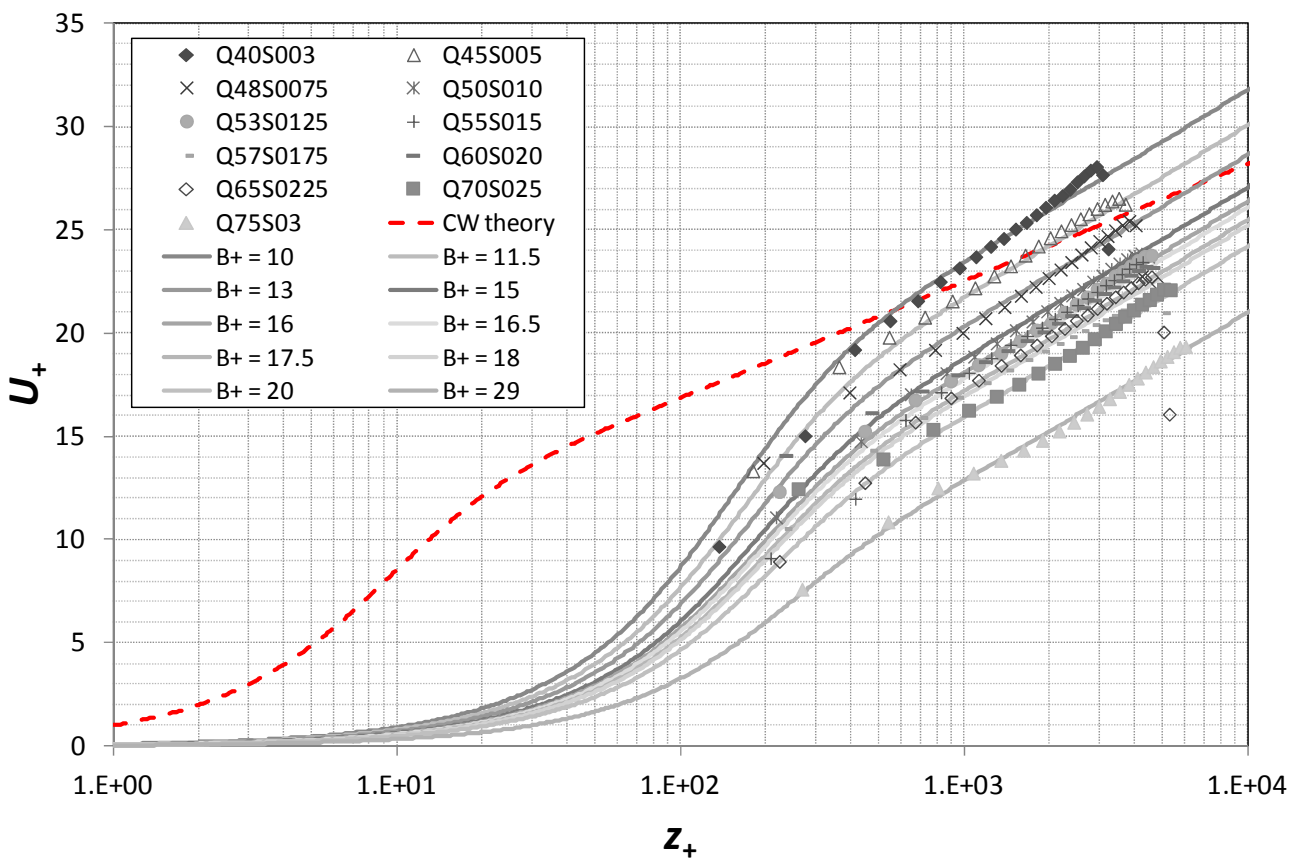

Figure 2. Comparison of non-dimensional velocity profiles by the Generalized Mixing-

Length model with flume data of CELLINO (1998) for sand suspension flow with increasing sediment load. Symbols $=$ measurements, full lines $=$ calculations, dashed line $=$ velocity profile for clear water, $B_{+}=G M L$ model parameter, proportional to the sediment concentration. $\left(U_{+}=U / u_{*}=\right.$ velocity $U$ non-dimensionalized by the shear velocity $u * ; z_{+}=z u * / v=$ distance from the bottom $z$ non-dimensionalized by the lengthscale $v / u *$ where $v=$ the kinematic viscosity of the ambient water).

A new generalized mixing-length (GML) turbulence closure has been developed, valid for both the low-Reynolds inner layer (down to the bottom) and the fully-developed outer layer, over smooth and rough surfaces without and with suspended particles (TOORMAN, 2012). It succeeds in simulating all sorts of profiles of velocity (figure 2), turbulent kinetic energy, Reynolds stress and sediment concentration found in the literature, with a minimal number of parameters.

In 3D models this GML model can be used as wall bridging method to determine more realistic near-bed boundary conditions for velocity, concentration, turbulent kinetic energy and its dissipation rate. At the same time it can be used as an alternative to estimate the bed load transport. This strategy thus far has only been tested in a 1DV version of the KULeuven research code FENST-2D, and is intended to be implemented and tested in a new Télémac 3D Scheldt estuary model, which is under construction. 
By integration of the corresponding velocity profile, it is possible to derive the equivalent Chézy roughness required in depth-averaged (2DH) models which are still commonly used in large-scale sediment transport studies.

Therefore, this new GML model provides an interesting tool for the analysis of data and can easily be implemented in numerical models as an alternative "bed load" transport module to provide new boundary conditions. The major shortcoming at this moment is the fact that this new model could not be tested (calibrated or validated) for cohesive sediments, for the simple reason that (to the author's knowledge) no suitable data exists where velocity, turbulence and concentration data have been measured over the vertical within an inner layer with high concentrations of suspended mud ( $>1 \%$ by effective volume occupied by the flocs).

\section{Turbulent Schmidt number}

The turbulent mixing (or entrainment) coefficient for the sediment particles (also known as eddy diffusivity), which appears in the turbulent flux term of the particle mass conservation (or sediment transport) equation, traditionally is assumed to be proportional to the eddy viscosity. The ratio of eddy viscosity to eddy diffusivity is known as the turbulent Schmidt number $\left(S c_{t}\right)$.

Many experimental data of measured concentration profiles have been analysed using the ROUSE theory (1937), which originally implicitly assumed $S c_{t}=1$. It was soon concluded that the Rouse number $\left(Z=w_{s} / \kappa u *\right.$, with $w_{s}$ the settling velocity, $\kappa$ the von Karman parameter and $u *$ the shear velocity $=\left(\tau_{0} / \rho\right)^{1 / 2}$, with $\tau_{0}$ the bottom shear stress and $\rho$ the bulk density) needed to be corrected with an empirical correction factor $\beta$, which corresponds to the inverse Schmidt number. However, no profile can be well matched with a single value for $\beta$. Analysis of the flume data with sand from CELLINO (1998) clearly shows that the profile needs to be split into two layers (TOORMAN, 2000): the outer layer corresponds to the fully developed turbulent layer, has dilute properties and a Rouse number below or equal to 1 . The inner layer, where lowReynolds conditions prevail (i.e. comprising the viscous sublayer at the bottom and the transition layer) and non-dilute conditions (four-way particle-turbulence interactions) exist, requires a Rouse number significantly larger than 1 .

Based on two-phase flow theory TOORMAN (2008 \& 2009) proposed a theoretical closure for the turbulent Schmidt number, which, for some of the rare data that provide sufficient details on turbulence, yields a nice match with the experimental data (TOORMAN, 2011). It is also demonstrated that the Schmidt number actually also includes another effect, the turbophoresis effect (the transport of particles from a region of high to a region of low turbulence intensity). At the same time, TOORMAN (2011) warns for the comparison of theory with experiments, since it is not always evident to know whether the measured data correspond to the fluid or to the particle movement, 


\section{XII ${ }^{\text {èmes }}$ Journées Nationales Génie Côtier - Génie Civil \\ Cherbourg, 12-14 juin 2012}

which can become significantly different near the bottom, especially under non-dilute conditions.

Analysis of various data with the GML model suggests that a constant Schmidt number of 0.7 can suffice for the outer layer, and for the inner layer, an empirical damping function should be applied, similar to other variables in the low-Reynolds modelling approach.

\section{Erosion}

The mass exchange at the interface with the bed is the final important difficulty in sediment transport modelling, and probably the most difficult one to be resolved.

With regard to the sedimentation flux, Krone's deposition law has often been misunderstood. The critical stress for deposition, which he introduced, has only a meaning in the context of 2DH modelling, where the depth-averaged concentration is computed, whereas the deposition flux is nothing else than the product of the sediment concentration and the vertical particle velocity at the bottom. By introducing the correction factor to the vertical flux computed with depth-averaged values, Krone actually describes the fact that part of the flux will not deposit because of the suspension capacity of the flow. Since 2DH models do not solve the vertical turbulent kinetic energy balance equation, it has no other way to account for the entrainment. It can be demonstrated from capacity theory how the "critical shear stress for deposition" can be computed theoretically.

Different erosion modes (i.e. surface erosion, soft mud erosion and mass erosion) have been recognized since the pioneering work of MIGNIOT (1968). The remainder of this section will focus on surface erosion and soft mud erosion.

The erosion flux is computed from erosion laws (such as the "Partheniades" law for cohesive sediments), which multiply an erosion rate with an erosion potential, based on a critical shear stress (or velocity). Computed concentrations of suspended sediment are very sensitive to the values of the two basic parameters of the erosion law and are usually used as tuning parameters, since it is very difficult to obtain accurate field data. The problem is furthermore complicated by the fact that the erosion parameters are expected to vary in space and time, because they are directly linked to bed properties.

Besides this practical problem, the fundamentals of the erosion law are still not well understood. There is still little understanding as to which strength parameter of the bed the critical stress for erosion should be related. Attempts have been made to relate it to geotechnical strength, such as vane shear strength, or rheological parameters, such as yield stress (BERLAMONT et al., 1993). The problem is also due to the problem of accurately measuring the erosion process, especially for fluid mud (an underconsolidated fresh deposit with density just above the gel point), which typically gives a value of the critical stress of the order of $0.1 \mathrm{~N} / \mathrm{m}^{2}$, which at the same time is the 
accuracy of the measurement (i.e. smaller values or values with two decimals accuracy cannot be measured reliably).

Then, there is the question of the value of the effort to account for the vertical bed structure by implementing a layered or continuous bed model. One can consider static models with a predefined density profile, or a more complex model allowing for consolidation. None of the existing models accounts for the counter acting force from the waves which may build up pore pressure and weaken the bed, the process known as fluidization. Observations along the Belgian and Guyana coasts suggest that fluid mud layers can persist under waves and never completely consolidate. The KULeuven Hydraulics Laboratory is currently working on the extension of SANFORD's (2008) bed model (computationally the most efficient approach) to include fluidization.

A bed model with a certain structure is necessary to control the availability of erodible sediment, since one can implement an empirical relationship between bulk density and erosion strength, varying with depth. However, it soon becomes complicated when a new fresh layer is deposited on top of the original layer. One may soon enter into a complex and computationally expensive book-keeping. Moreover, it requires knowledge of the vertical structure of the bed over the entire domain, which simply is impossible to obtain. Therefore, the uncertainty for accurate erosion modelling can be expected to remain very high.

Finally, there is the computation of the shear stress exerted by the flow on the bed surface. Traditionally, this done based on wall flow theory for clear water. Now the circle closes, since it has been discussed above that this shear stress may significantly be altered by the presence of a high-concentrated suspension on top of the bed. And how does this layer hinder the eroded sediment to be entrained immediately? In other words, it may be necessary to distinguish the erosion rate, often estimated indirectly from the increase in suspended sediment measured in the outer layer, although in reality it is the entrainment of sediment present in the inner layer and not coming from the bed itself. Once again, without proper measurement techniques revealing what is happening in the inner layer, this remains to be seen. But this layer is often so thin that it becomes practically very difficult or even impossible. However, the GML model may be a helpful tool to test various hypotheses.

\section{Sediment composition}

Sediments in the majority of natural habitats are composed of different anorganic minerals and organic materials of biogenic origin. Over the past decade some important progress has been made with regard to the modeling of simultaneous transport of mixtures of cohesive and non-cohesive (i.e. sand) particles. Until recently, sand and "mud" transport were studied independently, but this implies that all the turbulent entrainment energy is made available to each fraction. As the energy is used twice, it cannot represent reality. Of course the error is compensated by tuning the model 


\section{XII ${ }^{\text {èmes }}$ Journées Nationales Génie Côtier - Génie Civil \\ Cherbourg, 12-14 juin 2012}

parameters in order to calibrate the model with field data, but it should be realized that the necessary value no longer has physical meaning (e.g. the settling velocity can be increased to compensate for the overestimated entrainment flux).

A proper approach is to solve the transport of the two fractions at the same time, accounting for the integral particle-turbulence interaction in the TKE equation. This implies that the buoyancy destruction has to be applied using the total SPM concentration, and that the bulk density of the suspension should be used in the suspension momentum equations (which is especially important to correctly account for non-hydrostatic effects). Also, for hindered settling, the bulk concentration of all the fractions together has to be accounted for.

Recently, bed models have been proposed which can make a book-keeping of the relative content of sand and mud in each layer. This is important to keep control on the availability of the sediment fractions for erosion, as mentioned above. But it increases the need for knowledge of the distribution of the relative presence of sand and mud over the entire domain, both on the surface (which technically can be obtained from multibeam measurements) and into the depth (which is not yet possible, except by coring). Thus far, the most advanced modeling approach is the one recently developed by LE HIR et al. (2011), which is also implemented in the latest version (v6) of the Télémac code.

The prediction of the organic matter content will (most likely) remain a dream. Too many processes and parameters are involved. Implicitly, these particles are included in the cohesive fraction. Nevertheless, one must be aware of their presence and how they influence sediment transport processes, especially the structure and strength of flocs and mud deposits. At present, biogenic effects are hidden in the empirical values of sediment parameters such as critical erosion stress and floc kinetics rates. In some studies seasonal variations (e.g. due to algae bloom) are accounted for.

\section{Conclusions}

Despite much research efforts, little progress has been made over the past decades to improve the process models to such a level that they could be implemented efficiently into presently used 3D numerical models for sediment transport applicable to largescale engineering studies in coastal and estuarine areas.

Like weather models, it will remain very difficult to make accurate predictions of sediment transport, especially when the interest turns to long-term morphological impacts. One may wonder whether it would be possible to quantify the uncertainty of sediment transport models. There must exist a limit to the potential gain in accuracy by introducing more physics, while at the same time it becomes more and more difficult to calibrate the increasing number of model parameters, which again increases the uncertainty. 
New strategies under development at KULeuven have been presented in this paper. They have not yet been tested sufficiently to answer the question whether they allow significant improvement of 3D modelling. But they look promising, and the expected increase in computational cost seems acceptable.

It should be realized that the closures for bottom-flow interaction are all based on local equilibrium assumptions (i.e. only valid for steady currents). These closures should therefore also be tested in the future for time varying flows, representing tides and waves, and may need to be modified subsequently.

The most difficult problems remain the lack of knowledge of the vertical structure of the bed over an entire study area and the quantification of biogenic effects.

Much fundamental research in sediment transport remains to be done. However, the importance of this research is not sufficiently acknowledged by the stakeholders. Subsequently, too many studies are still carried out with the "old" models. Investment into fundamental research would speed up the improvement of the modelling tools, such that future engineering studies could make more accurate predictions, which would help stakeholders to make better decisions.

Acknowledgements: This review contains results and conclusions from past and ongoing projects in cohesive-sediment research funded in part by the: EU MAST3 project COSINUS (1997-2000), EU FP7 projects THESEUS and FIELD_AC (20102012), FWO project G.0263.08 (2008-2012), BelSPo project QUEST-4D (2008-2011) and the KULeuven Special Research Fund (2001-2011).

\section{References}

BERLAMONT J., OCKENDEN M., TOORMAN E., WINTERWERP J. (1993). The characterisation of cohesive sediment properties. Coastal Engineering, Vol. 21, pp 105-128. doi:10.1016/0378-3839(93)90047-C

CELLINO M. (1998). Experimental study of suspension flow in open channels. PhD Dissertation, Civil Eng. Dept., Ecole Polytechnique Fédérale de Lausanne.

KRONE R.B. (1962). Flume studies of the transport of sediment in estuarial shoaling processes. Final Report, Hydr. Engrg. Lab. \& Sanitary Engrg. Res. Lab., University of California, Berkely (CA), 118 p.

LEE B.J., TOORMAN E.A., MOLTZ F., WANG J. (2011). A two-class population balance equation yielding bimodal flocculation of marine or estuarine sediments. Water Research, Vol. 45, pp 2131-2145. doi:10.1016/j.watres.2010.12.028

LEE J., FETTWEIS M., TOORMAN E., MOLTZ F. (2012a). Multimodality of a particle size distribution of cohesive suspended particulate matters in a coastal zone. J. Geophysical Research, Vol. 117, C03014. doi:10.1029/2011JC007552 
LEE J., TOORMAN E., FETTWEIS M. (2012b). Flocculation of fine-grained cohesive sediments. Developing multimodal floc size distributions: field investigation and mathematical modeling. Submitted to Ocean Dynamics (Special Issue INTERCOH'11). LE HIR P., CAYOCCA F., WAELES B. (2011). Dynamics of sand and mud mixtures: A multiprocess-based modelling strategy. Continental Shelf Research, Vol. 31, pp S135-S149. doi:10.1016/j.csr.2010.12.009

LI M.Z., GUST G. (2000). Boundary layer dynamics and drag reduction in flows of high cohesive sediment suspensions. Sedimentology, Vol. 47, pp 71-86. doi:10.1046/j.13653091.2000.00277.x

MAERZ J., WIRTZ K. (2009). Resolving physically and biologically driven suspended particulate matter dynamics in a tidal basin with a distribution-based model. Estuarine, Coastal and Shelf Science, Vol. 84, pp 128-138. doi:10.1016/j.ecss.2009.05.015

MIGNIOT C. (1968). Etude des propriétés physiques de différents sédiments très fin et leur comportement sous des actions hydrodynamiques. La Houille Blanche, Vol. 7, pp 591-620. doi:10.1051//hb/1968041

PARTHENIADES E. (1962). A study of erosion and deposition of cohesive soils in salt water. PhD Dissertation, University of California, Berkely (CA).

ROUSE H. (1937). Modern conceptions of the mechanics of fluid turbulence. Trans. ASCE, Vol. 102, pp 463-543.

SANFORD L. (2008). Modeling a dynamically varying mixed sediment bed with erosion, deposition, bioturbation, consolidation and armoring. Computers \& Geosciences, Vol. 34, pp 1263-1283. doi:10.1016/j.cageo.2008.02.011

SUMER B. M., KOZAKIEWICZ A., FREDSØE J., DEIGAARD R. (1996). Velocity and concentration profiles in sheet-flow layer of movable bed. J. Hydraulic Eng., Vol. 122, pp 549-558. doi:10.1061/(ASCE)0733-9429(1996)122:10(549)

TOORMAN E.A. (2000). Numerical simulation of turbulence damping in sedimentladen flow. Part 2. Suspension capacity of uniform turbulent shear flows. Report HYD/ET/00/COSINUS4, Hydraulics Laboratory, K.U.Leuven.

TOORMAN E.A. (2008). Vertical mixing in the fully-developed turbulent layer of sediment-laden open-channel flow. J. Hydraulic Eng., Vol. 134(9), pp 1225-1235. doi:10.1061/(ASCE)0733-9429(2008)134:9(1225)

TOORMAN E.A. (2009). Errata and addendum for "Vertical mixing in the fullydeveloped turbulent layer of sediment-laden open-channel flow” by E.A. Toorman. J. Hydraulic Eng., Vol. 135(6), pp 538. doi:10.1061/(ASCE)HY.1943-7900.0000038

TOORMAN E.A. (2011). Closure to Discussions of "Vertical mixing in the fully developed turbulent layer of sediment-laden open-channel flow” by E.A. Toorman. J. Hydraulic Eng., Vol. 137(9), pp 1097-1100. doi:10.1061/(ASCE)HY.1943-7900.0000429

TOORMAN E.A. (2012). An efficient methodology for the incorporation of benthic high-concentrated suspension effects in cohesive sediment transport modeling. Submitted to Ocean Dynamics (Special Issue INTERCOH’11). 
Thème 2 - Dynamique sédimentaire

WANG J. (2011). Modelling techniques for the prediction of the floc size distribution of cohesive sediments. Research Report, FWO Project G.0263.08, Hydraulics Laboratory, KULeuven, 70 p.

WANG Z.Y., LARSEN P. (1994). Turbulent structure of water and clay suspensions with bed load. J. Hydraulic Eng., Vol. 120(5), pp 577-600. doi:10.1061/(ASCE)07339429(1994)120:5(577) 